\title{
Contribution of Spatial Heterogeneity and Temporal-Spatial Change of Ecosystems to the Thermal Environment of Tourist Destinations: A Case Study of Sichuan-Chongqing Region, China
}

\author{
Dechao Chen, ${ }^{1}$ Xinliang Xu, ${ }^{2}$ Huailong Jiang, ${ }^{3}$ Zongyao Sun, ${ }^{4}$ Luo Liu, ${ }^{5}$ and Zhi Qiao ${ }^{6}{ }^{6}$ \\ ${ }^{1}$ National and Local Joint Engineering Laboratory of Municipal Sewage Resource Utilization Technology, \\ Jiangsu Key Laboratory of Environmental Science and Engineering, School of Environmental Science and Engineering, \\ Suzhou University of Science and Technology, Suzhou 215009, China \\ ${ }^{2}$ State Key Laboratory of Resources and Environmental Information Systems, \\ Institute of Geographical Sciences and Natural Resources Research, Chinese Academy of Sciences, Beijing 100101, China \\ ${ }^{3}$ Shandong Land Survey and Planning Institute, Jinan 250014, China \\ ${ }^{4}$ School of Architecture, Tianjin University, Tianjin 300272, China \\ ${ }^{5}$ Guangdong Province Key Laboratory for Land Use and Consolidation, The College of Natural Resources and Environment, \\ South China Agricultural University, Guangzhou 510642, China \\ ${ }^{6}$ School of Environmental Science and Engineering, Tianjin University, Tianjin 300350, China
}

Correspondence should be addressed to Zhi Qiao; qiaozhi@tju.edu.cn

Received 3 February 2020; Accepted 8 June 2020; Published 23 June 2020

Academic Editor: Herminia García Mozo

Copyright (C) 2020 Dechao Chen et al. This is an open access article distributed under the Creative Commons Attribution License, which permits unrestricted use, distribution, and reproduction in any medium, provided the original work is properly cited.

Tourism development activities affect the structure and functions of ecosystems directly triggering changes in the thermal environment of tourism destinations and raising a need for sustainable development of the tourism industry. Using the 2005-2015 moderate resolution imaging spectroradiometer (MODIS) data on the land surface temperature combined with the land use data, the urban thermal environment contribution index (CI) of prefecture-level cities and ecosystem types corresponding to the study area in Sichuan-Chongqing region were quantitatively calculated under various seasonal and diurnal conditions in terms of the scales of administrative divisions and ecosystem types. The characteristics of the roles played by different cities and ecosystem types to contribute to the thermal environment of the metropolitan region were summarized, and the differences and changes in the corresponding contribution intensity of various ecosystem types were measured. The results indicate the following: (1) Different cities play different roles as the sources and sinks with respect to the thermal environment in the daytime and nighttime. Based on the diurnal differences of the contribution indices, cities can be divided into three types: the day-night heat source type, the day-sink and night-source type, and the day-night heat sink type. (2) The farmland and the grassland ecosystems are the most important source and sink landscapes in the thermal environment of the Sichuan-Chongqing Region, respectively. (3) The region is affected by the spatial arrangement of the internal ecosystems and its own development conditions, and, consequently, there are significant temporal-spatial variations and role transitions between heat source and heat sink regarding the contribution of different ecosystem types to the thermal environment of individual cities. It is important to scientifically regulate the thermal environment effect on tourism destinations and maintain the comfort and sustainable development through identifying the source and sink ecosystems of the thermal environment, controlling the quantity and spatial arrangement of the heat source ecosystems, and fully enabling the cooling effect of the heat sink ecosystems.

\section{Introduction}

The tourism industry is closely related to the climate $[1,2]$. The climatic environment is not only an external environmental condition that supports tourism activities but also an important tourism attraction itself [3]. With the development of the tourism industry in China, the rapid urbanization process of tourism destinations has led to 
dramatic changes in their ecosystems and has further impacted the climate [4]. Therefore, mitigating the risks caused by climate change and identifying efficient ways to deal with these problems are an important challenge in the development of tourism $[5,6]$.

Studies on thermal comfort are most common with respect to the climate environment of tourist destinations [7-9]. Early research was largely based on statistical empirical indicators including effective temperature (ET) index, wet bulb globe temperature (WBGT) index, temperaturehumidity (TH) index, and wind chill temperature (WCT) index $[10,11]$. The aforementioned empirical indicators are easy to calculate and understand for the public; however, they reduce the accuracy of the results and cannot meet the basic requirements of one-to-one correspondence between index values and the thermophysiological state of a human body. The empirical nature of these indicators also leads to the limitation of their application in time and space dimensions. As a result of the in-depth study of the human body heat transfer and energy metabolism, the universal thermal climate index (UTCI) based on the multinode thermophysiological model can be applied to many climate types $[12,13]$. It is sensitive to changes of climate elements and better describes the climate change process. However, these thermal comfort indicators are still not sufficiently sensitive to the climate changes caused by ecosystem changes, specifically to urban thermal environment estimates that have the most significant impact on the urban climate.

With the development of remote sensing technology, researchers have conducted significant research on monitoring and identification, evaluation and diagnosis, and simulation and regulation of the urban thermal environment [14-17]. As a result, they revealed in-depth information regarding the spatial and temporal patterns, evolution process, and formation mechanism of the urban thermal environment [18-21]. Various research studies were conducted on the spatial and temporal pattern, safety pattern, and risk prediction of the thermal environment in typical cities (Beijing, Shanghai, etc.) and at the national and global scale [22-25]. On the one hand, they mainly focused on the quantitative impact of specific land use types corresponding to the regional thermal environment, such as a degree of impact of impervious surface on the urban thermal environment, correlation between the urban green space landscape morphology and surface temperature $[26,27]$, and the spatial and temporal variation characteristics of the surface temperature affected by waters [28]. On the other hand, the quantitative relationship between the land cover and urban thermal environment was studied by remote sensing inversion of surface feature parameters, including Normalized Difference Vegetation Index (NDVI), Normalized Difference Build-Up Index (NDBI), and analysis of their relationship with the thermal environment [29-31]. Based on the aforementioned spatial and temporal quantitative relationship between the land use/ cover and thermal environment, a comprehensive evaluation model was established to identify the temporal and spatial patterns of the urban thermal environment and to predict thermal environmental risks [14].
Based on the aforementioned research, in the process of exploring the impact of different land use/cover on the urban thermal environment, most analytical methods involve establishing a linear relationship between the land use/cover and surface temperature and analyzing the temporal and spatial trends. This result can only indicate whether there is a correlation between a particular land use type and the thermal environment. However, as a complex giant system, the urban thermal environment is impacted by ecosystems that serve as its matrix to various degrees on the temporal and spatial scales. Considering tourism destinations, which are the special cases of urbanization, the essential scientific question of this study is how to quantitatively analyze the spatial and temporal contributions of different ecosystem types to the regional thermal environment on different time and space scales, so as to provide theoretical basis and technical support for scientifically and efficiently regulating the climate environment of tourism destinations.

\section{Research Area and Data}

2.1. Overview of the Study Area. The Sichuan-Chongqing region is a typical urban area in southwestern China and an important tourist destination (Figure 1). The SichuanChongqing region is located in the Sichuan Basin and the eastern part of Wushan mountain area including Sichuan Province and Chongqing City. The four sides of this region spread from $97^{\circ} 22^{\prime}-110^{\circ} 12^{\prime} \mathrm{E}$ and $26^{\circ} 02^{\prime}-34^{\circ} 18^{\prime} \mathrm{N}$, with a total area of $568,100 \mathrm{~km}^{2}$. The terrain of this area is complex and high in the northwest and low in the southeast, with mountains and basins as the main geomorphological types, and the plains only account for $2.6 \%[32,33]$.

2.2. Data Source. The surface temperature data used in this study are obtained from the moderate resolution imaging spectroradiometer (MODIS) 8-day synthetic surface temperature product (MYD11) provided by NASA. The raw data were obtained by the Aqua satellite, when it passed the earth at $1: 30 \mathrm{pm}$ and $1: 30 \mathrm{am}$ indicating the temperature rising and cooling periods on the surface, respectively. The data product was obtained by inversion with the Split-Window algorithm with a precision of $1 \mathrm{~K}[34,35]$.

The ecosystem-type data are obtained from the 1:100,000 China land use status remote sensing monitoring dataset provided by the Resource and Environmental Science Data Center of the Chinese Academy of Sciences. The dataset consists of six primary land-use types, cultivated land, forestland, grassland, waters, urban and rural land, and unused land, and 25 secondary land-use types. It has been verified that the average precision of classification for cultivated, urban, and rural use types of land is over $85 \%$, and the average precision of classification for other land use types is greater than $75 \%$. This dataset has been widely used in the spatiotemporal pattern analysis of the urban (group) thermal environments and the comprehensive assessment of the ecological effects. According to the current ecological environment of the Sichuan-Chongqing region, in this study, the dataset was reclassified into farmland, forest, grassland, 

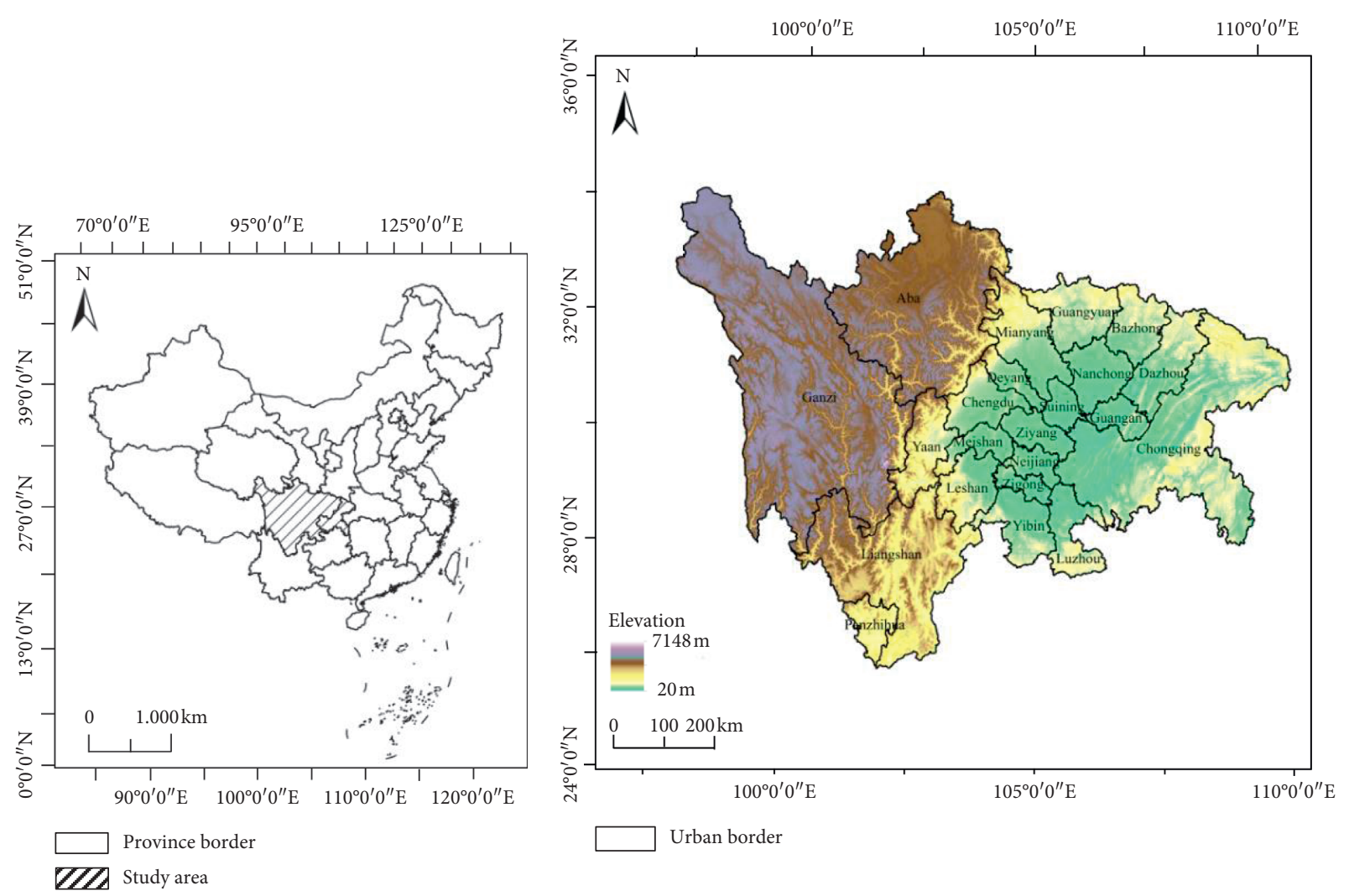

FIgURE 1: The location and elevation of the study area.

water body and wetland, urban land, rural land, and desert ecosystems (Figure 2) [36].

\section{Research Methods}

3.1. Surface Temperature Data Processing. The MODIS surface temperature product only records the heat radiation values of the surface under cloudless conditions that need to be converted to the surface temperature.

The surface temperature can be calculated using the following equation [37]:

$$
T_{S}=\mathrm{DN} \times 0.02-273.15 \text {, }
$$

where $T_{\mathrm{s}}$ is the surface temperature (unit: ${ }^{\circ} \mathrm{C}$ ) and $\mathrm{DN}$ is the digital number assigned to a pixel.

To compare the time variation in the impact of different ecosystem types on the regional thermal environment, the 8day synthetic data of the surface temperature were further combined to calculate the seasonal and diurnal averages corresponding to four seasons, spring (March, April, and May), summer (June, July, and August), autumn (September, October, and November), and winter (December, January, and February), between 2005 and 2015 (Figure 3).

3.2. Thermal Environment Contribution Index (CI). The underlying surface of a region is a complex subject composed of various ecosystems. Due to various topography, functions, and development stages of different cities, the spatial patterns of their ecosystems present a substantial spatial heterogeneity, and, consequently, the mechanism of influence on the regional thermal environment also shows some temporal and spatial differences. According to the different impacts of different ecosystem types on the regional thermal environment, the ecosystems are considered as the sources or sinks of the regional thermal environment. The contribution of the source/sink landscapes to the regional thermal environment can be quantitatively characterized by the contribution index, which is the product of the difference between the average surface temperature of an ecosystem type and the regional average temperature multiplied by the area proportion of the ecosystem type to the whole region (equation (2)). The positive and negative signs of the contribution index of the ecosystem type indicate whether this ecosystem is heating (source) or cooling (sink) the regional thermal environment, and the magnitude of the index represents the degree of contribution of the ecosystem type to the regional thermal environment $[22,38]$ :

$$
\mathrm{CI}=D_{t} \times S,
$$

where $\mathrm{CI}$ is the contribution index of the ecosystem type to the regional thermal environment, $D_{t}$ is the difference between the average surface temperature of a certain ecosystem type in the region and the regional average temperature, and $S$ is the area proportion of a certain ecosystem type to the region. Similarly, the contribution of different cities to the regional thermal environment is calculated as the product of the difference between the average surface temperature of 


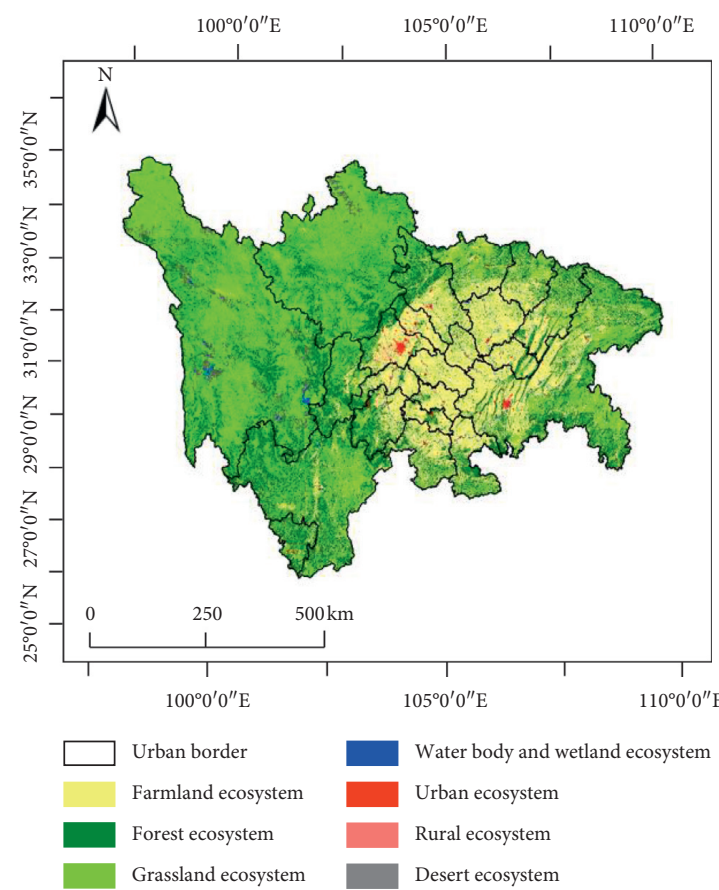

(a)

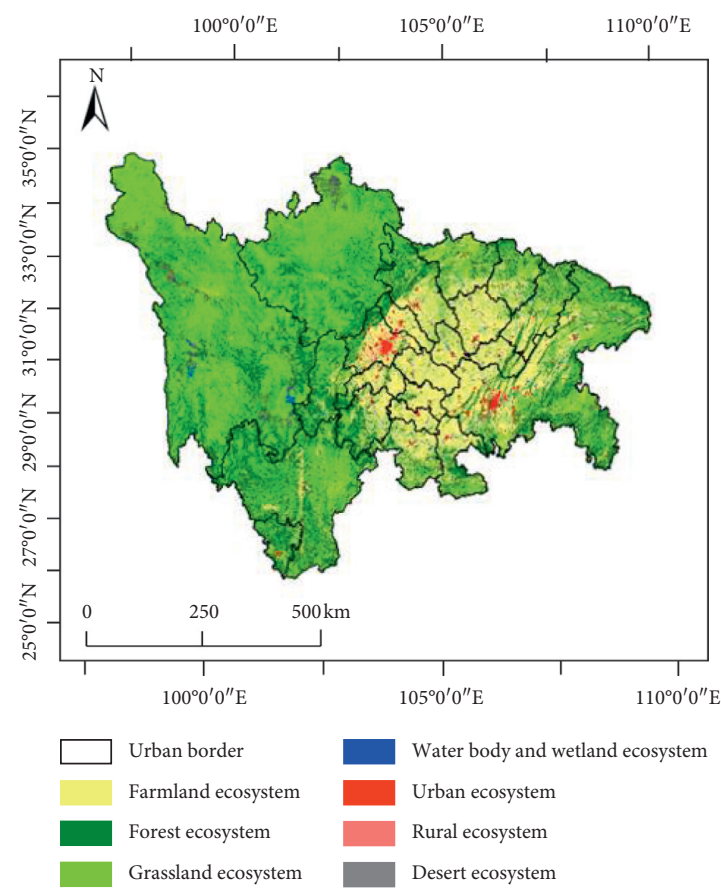

(b)

Figure 2: The spatial distribution of ecosystem between 2005 and 2015 in Sichuan-Chongqing region. (a) 2005. (b) 2015.

the individual cities and the regional average temperature multiplied by the proportion of the area occupied by the city.

\section{Results}

\subsection{Variations in Contributions of Different Cities in Sichuan- Chongqing Region to the Thermal Environment}

4.1.1. Interannual Variations. Considering prefecture-level cities as a statistical unit, the variations in contribution across different cities in Sichuan-Chongqing region to the regional thermal environment between 2005 and 2015 were analyzed (Figure 4). The contribution indices of the Aba Tibetan and Qiang Autonomous Prefecture and the Ganzi Yi Autonomous Prefecture to the regional thermal environment were considerably below zero. These areas demonstrated a strong cooling effect, which acted as the sink of the thermal environment of the Sichuan-Chongqing region. The City of Ya'an's contribution index was less than 0 during the day and greater than 0 during the night. It indicates that the role of the city as a source/sink to the thermal environment switched between daytime and nighttime, showing a cooling effect during the day and a heating effect at night. The diurnal and nocturnal contribution indices of other cities were greater than 0 , illustrating that these cities always had temperatures higher than the average temperature of the urban agglomeration, and, consequently, they acted as the heat sources of the region. According to the average annual contribution to the thermal environment, all cities can be divided into three types: the day-night heat source type $(\mathrm{CI}>0)$, the day-sink and night-source type $(\mathrm{CI}<0$ in daytime and $\mathrm{CI}>0$ in nighttime), and the day-night heat sink type $(\mathrm{CI}<0)$ referring to the City of Chongqing, Ya'an, and Ganzi Yi Autonomous Prefecture as the representatives for each of the types, respectively.

Comparing the interannual changes in the contribution of cities to the thermal environment of the Sichuan-Chongqing region between 2005 and 2015, it is deemed that the roles of individual cities as a source/sink to the thermal environment did not change. However, the cities of Chongqing, Meishan, and Ziyang contributed more to the thermal environment of Sichuan-Chongqing region in 2015 than in 2005, while the absolute values of the contributions to the thermal environment by other cities in 2015 were less than those in 2005. From the comparison analysis of intensity of contributions, it can be seen that the temperature differences between cities in 2015 were reduced relatively to 2005 , which was indicated by a smaller range of the contributions. The contribution of Chongqing that showed the most significant heat source effect was reduced from 0.77 to 0.54 , while the contribution index of Ganzi Tibetan Autonomous Prefecture, the city with the most significant sink effect, increased from -1.54 to -1.19 . During 2005-2015, similar variation trends were observed for the nighttime and the daytime with decrease in the range of the contributions to the thermal environment and with the nighttime change being smaller than that during the day. In terms of diurnal differences, the interannual difference between day and night contributions from 2005 to 2015 increased significantly. As a representative of the day-night heat source type, Chongqing had an increase in the difference of diurnal contributions from 0.50 to 0.69 , while the difference in Ganzi, a representative of the day-night heat sink type, decreased from -1.03 to -1.33 .

In summary, the Sichuan-Chongqing region is subject to the impact of surrounding terrains, and the thermal landscape of each city varies significantly. From 2005 to 2015, the 


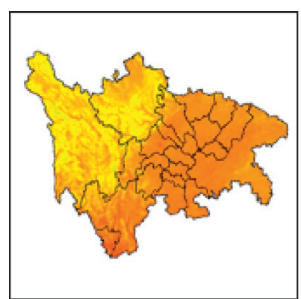

(a)

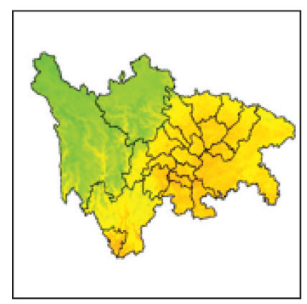

(e)

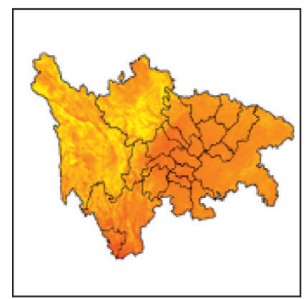

(i)

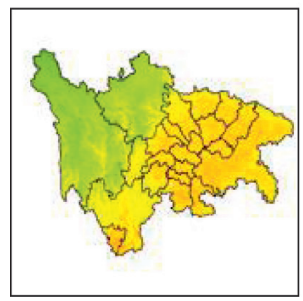

(m)

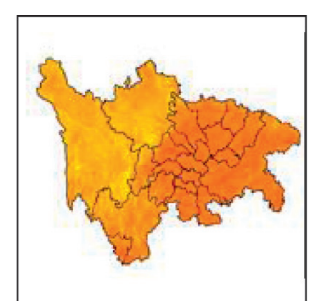

(b)

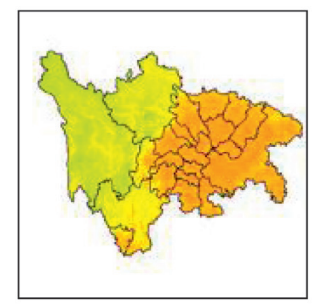

(f)

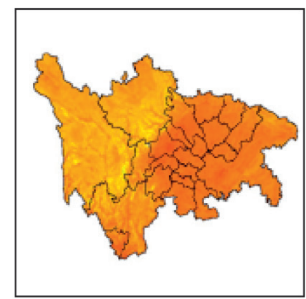

(j)

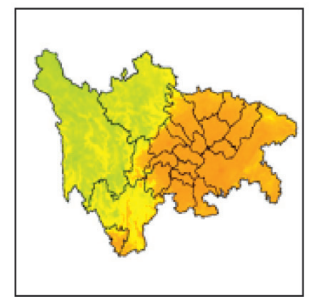

(n)

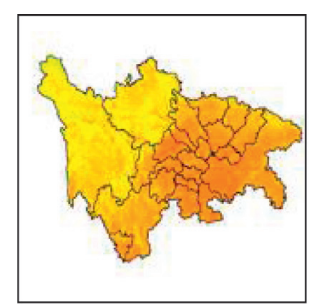

(c)

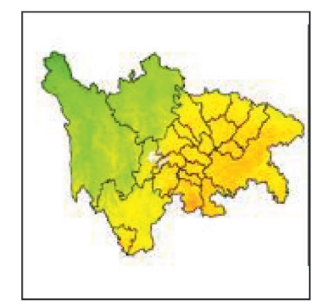

(g)

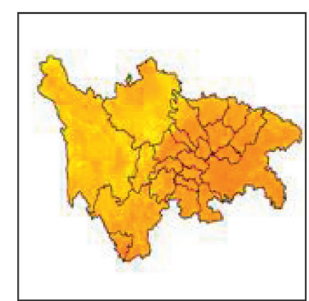

(k)

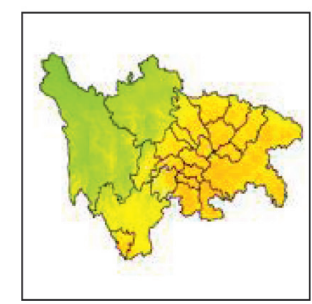

(o)

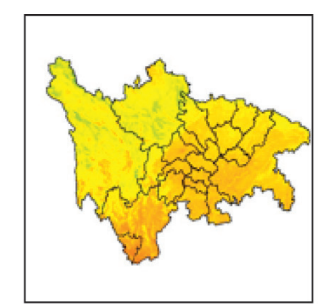

(d)

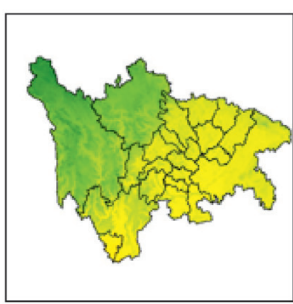

(h)

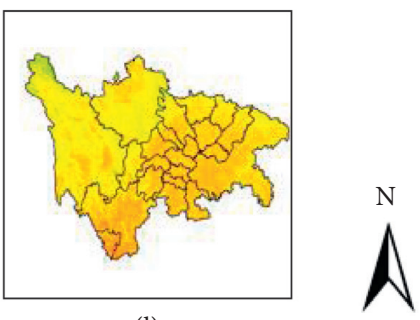

(1)

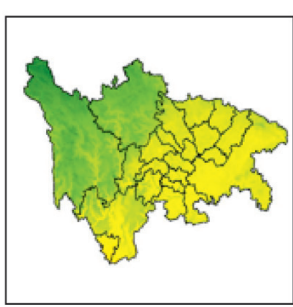

(p)
$N$

$\operatorname{LST}\left({ }^{\circ} \mathrm{C}\right)$

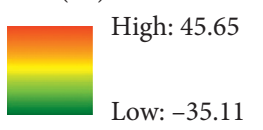

Figure 3: The spatial distribution of land surface temperature between 2005 and 2015 in Sichuan-Chongqing region. (a) 2005 spring daytime. (b) 2005 summer daytime. (c) 2005 autumn daytime. (d) 2005 winter daytime. (e) 2005 spring nighttime. (f) 2005 summer nighttime. (g) 2005 autumn nighttime. (h) 2005 winter nighttime. (i) 2015 spring daytime. (j) 2015 summer daytime. (k) 2015 autumn daytime. (l) 2015 winter daytime. (m) 2015 spring nighttime. (n) 2015 summer nighttime. (o) 2015 autumn nighttime. (p) 2015 winter nighttime.

anthropogenic heat emissions affected the spatial distribution of heat in the urban agglomerations and, therefore, rendered the thermal environment of individual cities in the agglomeration to converge. The magnitude of variations in the contribution of individual cities to the thermal environment was significantly higher during daytime than during nighttime, and the diurnal difference was further widened, specifically in the typical source and sink cities.

4.1.2. Seasonal Variations. The contributions of different cities in the Sichuan-Chongqing region to the regional thermal environment in different seasons in 2015 were compared (Figure 5). Based on the city types, similar to the characteristics of interannual contribution, the thermal environment contribution indices of Aba Prefecture and Ganzi Prefecture in different seasons were less than 0, still corresponding to a typical day-night heat sink type, and the nighttime cooling effect was significantly higher than that of the daytime. The thermal environment contribution index of Ya'an fluctuated at 0 , below 0 during daytime, and above 0 at nighttime, indicating a source/sink role transition between daytime and nighttime. Other cities showed thermal environment contribution indices above 0 in different seasons. Regardless of seasonal and diurnal variations, these cities acted as heat sources in the thermal environment of the urban agglomeration. 


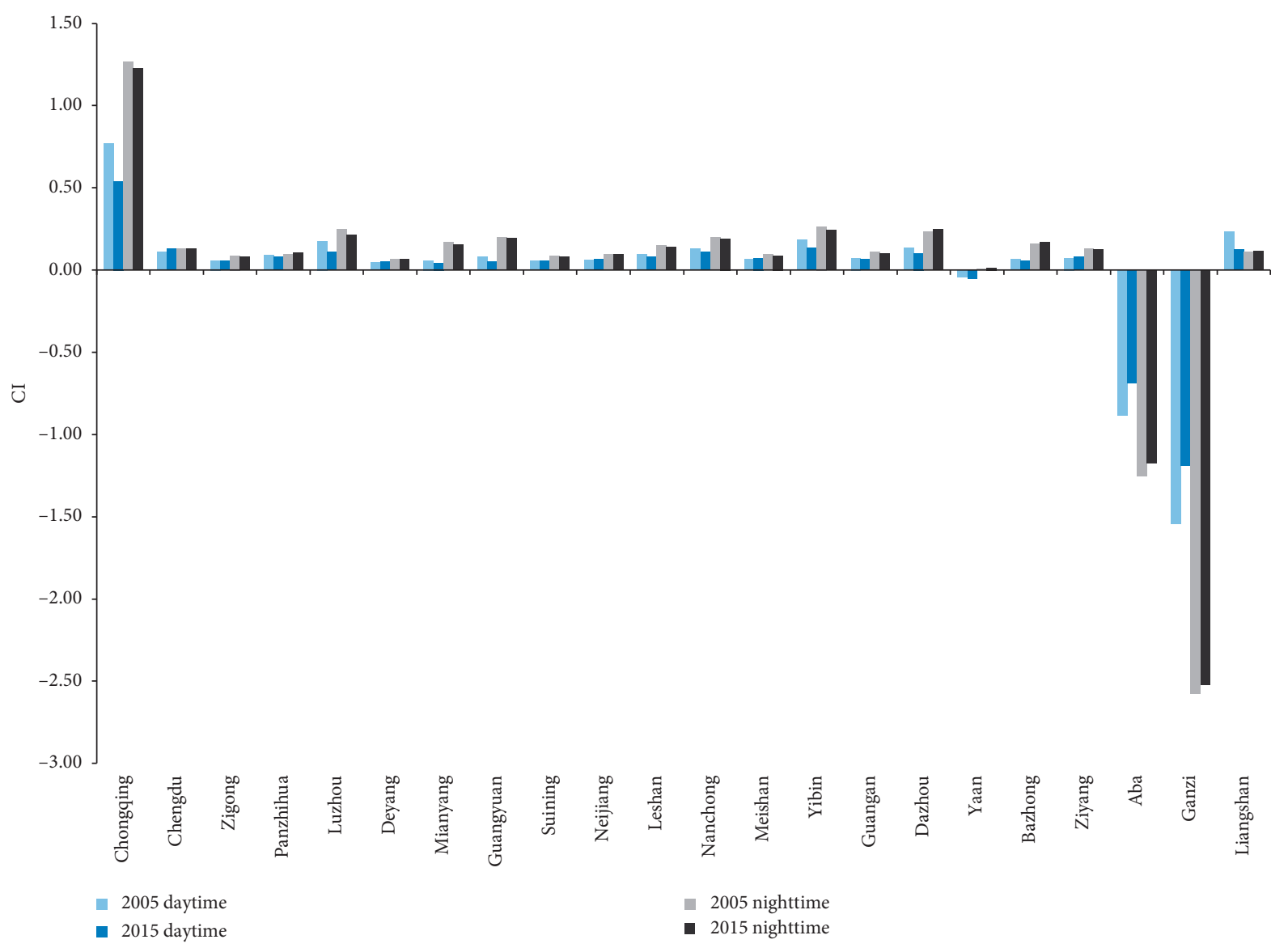

Figure 4: The thermal environment contribution indices of 22 cities for the Sichuan-Chongqing region between 2005 and 2015.

Comparison of the seasonal differences in the contribution of different cities to the thermal environment of the urban agglomeration showed that, except for Liangshan Yi Autonomous Prefecture, other cities maintained a relatively stable trend. During the daytime, the contribution indices were lower in spring and winter and higher in summer, with the smallest differences among cities in winter. Seasonal source/sink transitions were observed in some cities. Considering the cities of Mianyang, Guangyuan, and Bazhong, the contribution indices in winter were less than 0 , referring them as sinks of the regional thermal environment, while the contribution indices in other seasons were greater than 0 , referring them as heat source cities. At the nighttime, the seasonal variations in contribution indices of individual cities were smaller than those of the daytime, and the range of the maximum seasonal contribution was only 0.3 . The seasonal contribution pattern of Liangshan Yi Autonomous Prefecture was different from those of other cities in the SichuanChongqing region, as it exhibited significant cooling effect in summer and heating effect in winter. The intensity at night was slightly higher than that of the daytime, and the heating effect at night was weaker than that of the daytime in spring.

\subsection{Variations in the Contributions of Different Ecosystem Types to the Thermal Environment of the Sichuan- Chongqing Region}

4.2.1. Interannual Variations in the Contributions of Various Ecosystem Types to the Thermal Environment of the SichuanChongqing Region. Forest and grassland ecosystems are the main land use types in the Sichuan-Chongqing region with area ratios greater than $30 \%$ and are mostly distributed in mountainous areas (Table 1). Farmland ecosystem is the next in terms of size, with an area ratio of $27.91 \%$; water body and wetland ecosystems are presented relatively limitedly, accounting for only $1 \%$. The proportions of both urban and rural ecosystems serve as carriers for human life and production activities less than $1 \%$. The desert ecosystem accounts for $3.1 \%$. The differences between the temperatures of various ecosystem types and the average temperature of the Sichuan-Chongqing region were compared, and the results indicated that the forest, grassland, and desert ecosystems were the sinks; and other ecosystems acted as the sources of the thermal environment of the Sichuan-Chongqing region. The changes in individual ecosystem areas, the differences between their temperatures, and the average temperature from 2005 to 2015 were compared. The overall change in the 


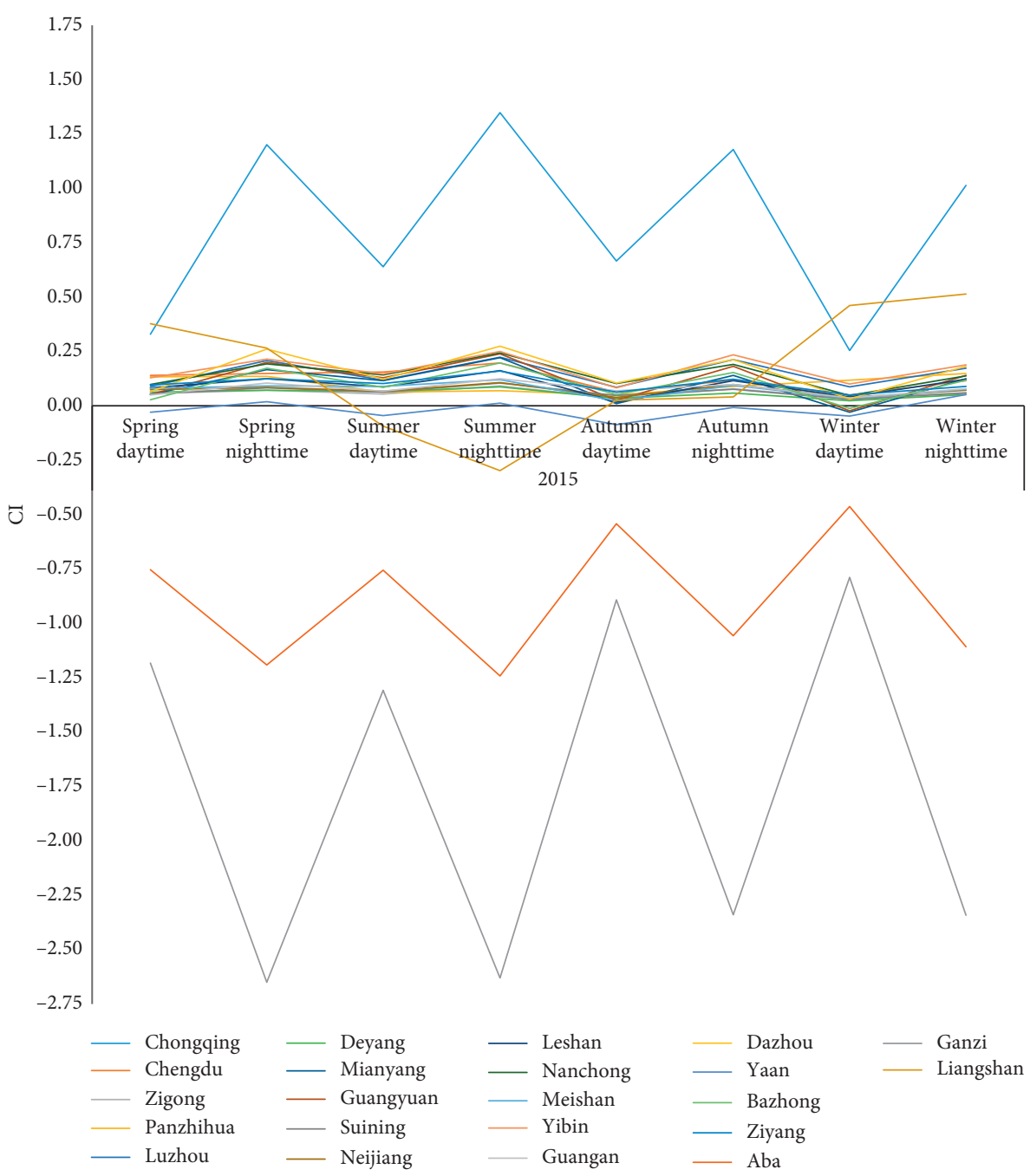

FIgURE 5: The seasonal CIs of 22 cities in the Sichuan-Chongqing region in 2015.

TABle 1: The CI of different ecosystem types for Sichuan-Chongqing region between 2005 and 2015.

\begin{tabular}{|c|c|c|c|c|c|c|}
\hline \multirow{2}{*}{ Ecosystem } & \multicolumn{3}{|c|}{2005} & \multicolumn{3}{|c|}{2015} \\
\hline & Area proportion (\%) & Deviation & $\mathrm{CI}$ & Area proportion & Deviation & $\mathrm{CI}$ \\
\hline Farmland & 27.91 & 6.14 & 1.71 & 27.36 & 5.21 & 1.43 \\
\hline Forest & 34.61 & -0.40 & -0.14 & 35.45 & -0.86 & -0.30 \\
\hline Grassland & 32.83 & -3.97 & -1.30 & 31.71 & -3.06 & -0.97 \\
\hline Water body and wetland & 0.82 & 1.78 & 0.01 & 1.00 & 1.70 & 0.02 \\
\hline Urban land & 0.34 & 9.07 & 0.03 & 0.90 & 8.07 & 0.07 \\
\hline Rural land & 0.40 & 7.16 & 0.03 & 0.47 & 6.99 & 0.03 \\
\hline Desert land & 3.10 & -8.27 & -0.26 & 3.12 & -5.89 & -0.18 \\
\hline
\end{tabular}

ecological system of the Sichuan-Chongqing region was relatively minor; however, the urban ecosystem increased significantly, with an increase in the proportion of the area from $0.34 \%$ to $0.90 \%$. Farmland and the grassland ecosystems decreased slightly. In 2005, the temperatures of urban, rural, and farmland ecosystems were all above the regional average temperature by $6^{\circ} \mathrm{C}$, while the temperatures of desert ecosystems were below the regional average temperature by more than $8^{\circ} \mathrm{C}$, indicating clearly their roles as sources or sinks, and the difference was obvious. In 2015, the differences between individual ecosystem types and the average temperature declined; and the average temperature of the urban ecosystem decreased by $1^{\circ} \mathrm{C}$, the farmland decreased by $0.93^{\circ} \mathrm{C}$, desert increased by $2.38^{\circ} \mathrm{C}$, and the overall intensity difference between sources and sinks was reduced.

The changes in the contributions of various ecosystems to the thermal environment of Sichuan-Chongqing region between 2005 and 2015 were compared. As a heat source of the urban agglomeration, the rural ecosystem maintained 
stable contribution to the regional thermal environment. The contribution of the urban ecosystem to the regional thermal environment increased from 0.03 to 0.07 , while that of the farmland ecosystem decreased from 1.71 to 1.43 , still corresponding to the ecosystem with the most significant warming effect in the Sichuan-Chongqing region. Among the ecosystem types serving as heat sinks of the SichuanChongqing region, the grassland ecosystem still showed the most significant cooling effect; however, its contribution index increased from -1.30 to -0.97 during $2005-2015$. The contribution indices of the forest and desert ecosystem exhibited two opposite trends, indicating that the cooling effect of the forest ecosystem was further enhanced, while the cooling effect of the desert ecosystems was significantly weakened.

4.2.2. Seasonal Variations in the Contributions of Ecosystems to the Thermal Environment of the Sichuan-Chongqing Region. Comparative analysis of seasonal variations in contribution indices of different ecosystem types to the thermal environmental was conducted (Figure 6). The contributions of the water body and wetland ecosystems and rural ecosystem to the thermal environment of the SichuanChongqing region were close to zero. Water body and wetland ecosystems have high specific heat capacity [22]. The average temperatures of these two ecosystems did not differ significantly from the average temperature of the Sichuan-Chongqing region. Therefore, the contributions of both water body and wetland ecosystems and rural ecosystem to the regional thermal environment were not substantial, showing slightly higher contribution in summer compared with other seasons. The seasonal and diurnal contributions of the grassland and desert ecosystems to the thermal environment of the Sichuan-Chongqing region were less than 0 , indicating a relatively strong cooling effect. In the summer nights, the difference between the grassland ecosystem temperature and the regional average surface temperature reached $7.15^{\circ} \mathrm{C}$, showing the strongest cooling effect. During the daytime, the cooling effect of the grassland ecosystem was weaker than that of nighttime. The cooling effect varied greatly across different seasons, while the nighttime variations were relatively small. The contribution variation of the desert ecosystem to the thermal environment of the Sichuan-Chongqing region was small with a stronger cooling effect at night than during the day. The cooling effect in spring was stronger than that in other seasons. The daytime and nighttime contribution indices were -0.21 and -0.38 , respectively. The seasonal and diurnal variations in contributions of the farmland ecosystem to the thermal environment were substantial. The nighttime warming effect of the farmland ecosystem was significantly higher than that of the daytime with the highest contribution in summer and the lowest one in winter. As the most significant heat source of the Sichuan-Chongqing region, the diurnal variation of thermal contribution of farmland ecosystem results from its smaller thermal inertia, causing the temperature to drop more rapidly than forest [22]. While the seasonal variation of thermal contribution of farmland ecosystem is because of the activities of farming in different seasons and types of activities involved, the latter can possibly be related to the greenhouse gas emissions from these agricultural activities that might produce heat trapping substances. The diurnal variations in contributions of the urban ecosystem to the thermal environment of the SichuanChongqing region were not obvious. The contribution was higher in summer than in other seasons and lowest in winter. The forest ecosystem was observed to be the most special type in terms of the characteristics of contributions to the thermal environment in the Sichuan-Chongqing region. The daytime contributions were less than 0 , showing a very clear cooling effect. The summer thermal environment contribution index reached -0.34 , and the cooling effect was the second after that of the grassland ecosystem. Except for summer, the forest ecosystem was transformed into a heat source of the thermal environment at the nighttime. The contribution index of winter night reached 0.55 , which was the second after that of the contribution of the cultivated land ecosystem. The LST of forest was lower than that of farmland ecosystem in the daytime but higher at night, showing that the LST of forest changes lower than that of farmland. It also can be inferred that thermal inertia was a significant cause of the diurnal LST variations. By contrast, the forest has larger thermal inertia than that of farmland; thus, the LST of forest changed much slower than that of farmland, which explains the diurnal change in the roles of farmland and forest [22].

4.3. Variations in Contributions of Different Ecosystems to the Thermal Environment within Cities. To perform further comparison of the spatial variations in the contributions of different ecosystems to the thermal environment, the prefecture-level cities were considered as the research unit to calculate the thermal environment contribution indices of different ecosystem types in various seasons and daytime/ nighttime (Figure 7).

During the day, both urban and rural ecosystems were observed to behave as heat sources. In spring, in most cities, farmland ecosystem was characterized as heat source ecosystems and the forest ecosystem as a heat sink ecosystem. Among those systems, the urban ecosystem of Chengdu provided the maximum contribution index of 0.43 to the thermal environment. The contributions of the urban ecosystems in Aba Prefecture and Ganzi Prefecture were less than 0.01. Except for Suining and Ziyang, the warming effect of farmland ecosystem in other cities was significant, specifically in Mianyang, with the index reaching 1.56 . The contribution indices of forest ecosystems in all cities besides Ziyang and Ganzi were less than 0 , among which the cooling effect of the Chengdu's forest ecosystem was the most significant with a contribution index of -1.15 . Other ecosystem types within different cities did not exhibit regular source or sink patterns. The contribution of the desert ecosystem in Aba Prefecture was significantly higher compared to those of other cities reaching 0.25 . The contribution of the grassland ecosystem in Mianyang was as low as -0.95 , indicating that it served as the most important type of a cooling ecosystem in 


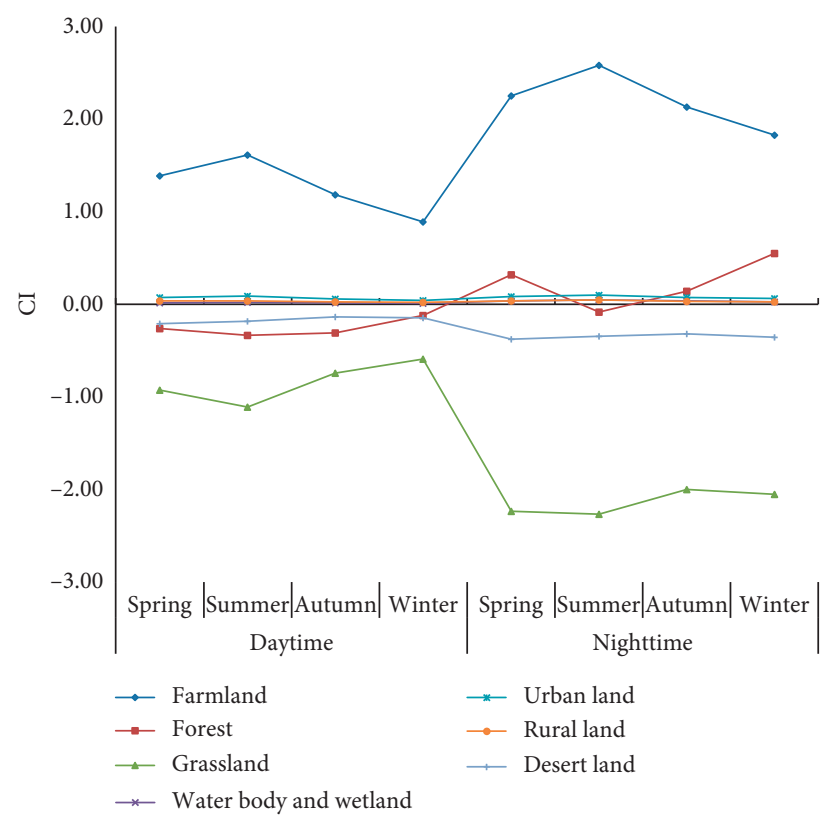

Figure 6: The seasonal CIs of different land use types for the regional thermal environment in 2015.

the city. The contribution of the grassland ecosystem in Ganzi Prefecture was 0.3, which is substantially higher than that in other cities. In summer, the forest ecosystem of Ganzi Prefecture was transformed from a heat source to a heat sink, while the roles of ecosystems in other cities were basically the same as those in spring. However, the solar radiation was enhanced in summer, and the overall warming and cooling effects of various ecosystem types in the cities were more obvious [22]. As a result, the range of the contributions of the same type of ecosystems to the thermal environment of different cities increased, and, similarly, the range of the contributions of different source/sink ecosystems to the thermal environment within cities also arose. The ranges of the contributions of farmland ecosystem and grassland ecosystem were at 1.70 (Mianyang-Ziyang), and -1.34 (Ganzi-Mianyang), respectively. The ranges of the contributions of source/sink lands were 2.71 (farmland ecosystemgrassland ecosystem) for Mianyang and 2.25 (farmland ecosystem-forest ecosystem) for Leshan. In relation to summer, autumn was characterized with declining contributions of various ecosystem types to the thermal environment, which was mainly represented as the increase in the grassland ecosystem contribution index in Mianyang to -0.83 , indicating a weakened cooling effect. In winter, affected by vegetation phenology, the contributions of the individual urban ecosystems varied to a less extent, and the variations of the same ecosystem within different cities were also smaller. In addition, the role of the forest ecosystem in Ganzi Prefecture changed from a heat source type in spring and summer to a heat sink type ecosystem in winter. Comprehensive comparison of the contributions of ecosystems to the urban thermal environment during the daytime indicated that there were no significant changes in the roles of the ecosystems serving as a source or sink. However, with the change of seasons, the impact intensity of ecosystem contributions to the thermal environment of each city changed. The contributions of ecosystems to the thermal environment varied to a greater extent in spring and summer in comparison with autumn and winter.

At night, farmland, urban, and rural ecosystems all acted as heat source, while grassland ecosystem served as heat sink. Other ecosystems showed various contributions to the thermal environment in different cities. In spring, farmland ecosystems showed a strong warming effect, which was significantly higher than that for other ecosystem types, with that of Mianyang reaching 1.13. The cooling effect of grassland ecosystems was obvious, and their corresponding contributions in Leshan and Mianyang were -0.85 and -0.59 , respectively. However, the forest ecosystems in Ganzi Prefecture and Aba Prefecture were acting as heat sources with the contribution index above 0.59 . Forest ecosystems in other cities still appeared as heat sink on spring nights. In summer, the warming effect of farmland ecosystems was enhanced, among which the contribution of farmland ecosystems in Mianyang to the thermal environment exceeded 1.4. The cooling effect of forest and grassland ecosystems was also more significant. The contributions of forest ecosystems in Leshan and grassland ecosystem in Mianyang were below -0.8 , and the warming effect of forest ecosystem in Ganzi Prefecture and Aba Prefecture was weakened. Similarly, in autumn, the contribution indices of farmland, forest, and grassland ecosystems were subject to seasonal impacts. Among them, the contribution indices of farmland and grassland ecosystems in Leshan reached 1.41 and -1.12 , respectively. In winter, the cooling effect of farmland ecosystems in various cities was significantly weakened, and the maximum contribution index to the thermal environment was only 0.84 (Mianyang), which was lower than that in summer by 0.45 . The contributions of the forest ecosystem in Ganzi Prefecture and Aba Prefecture to 

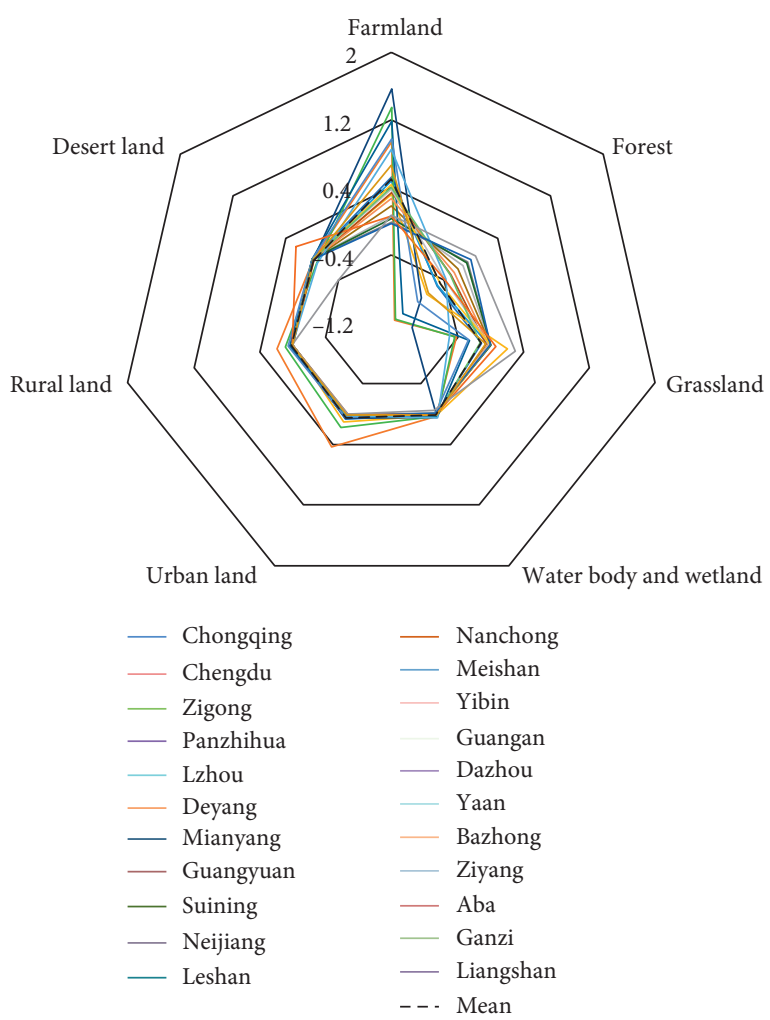

(a)
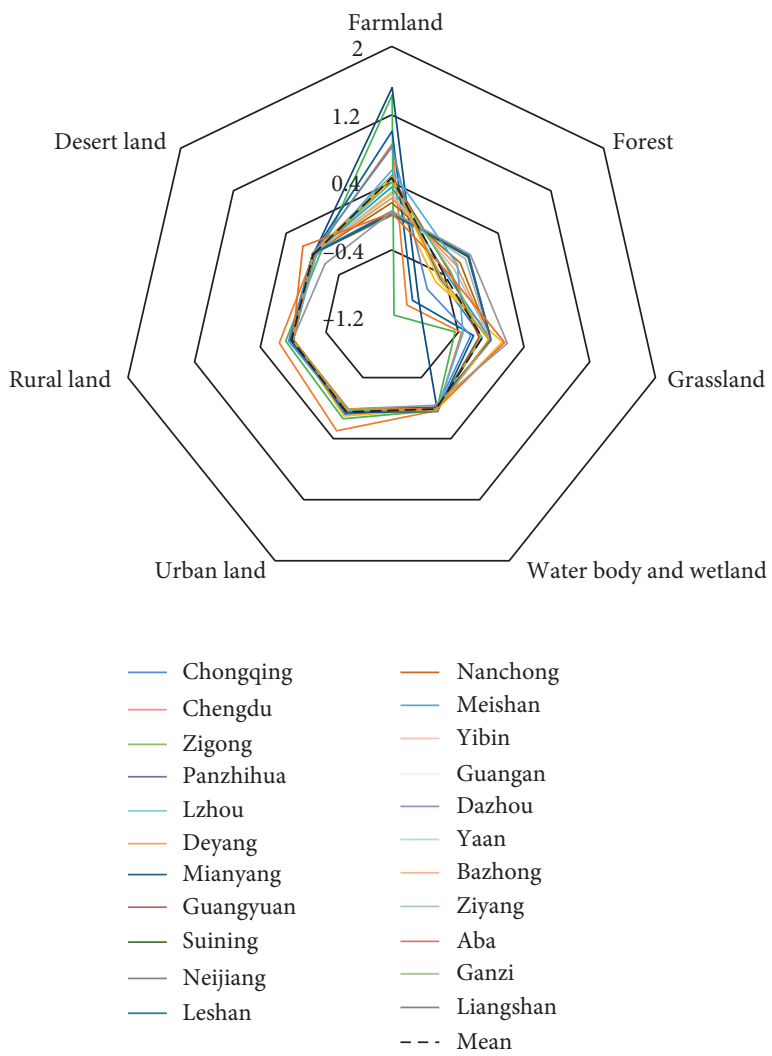

(c)
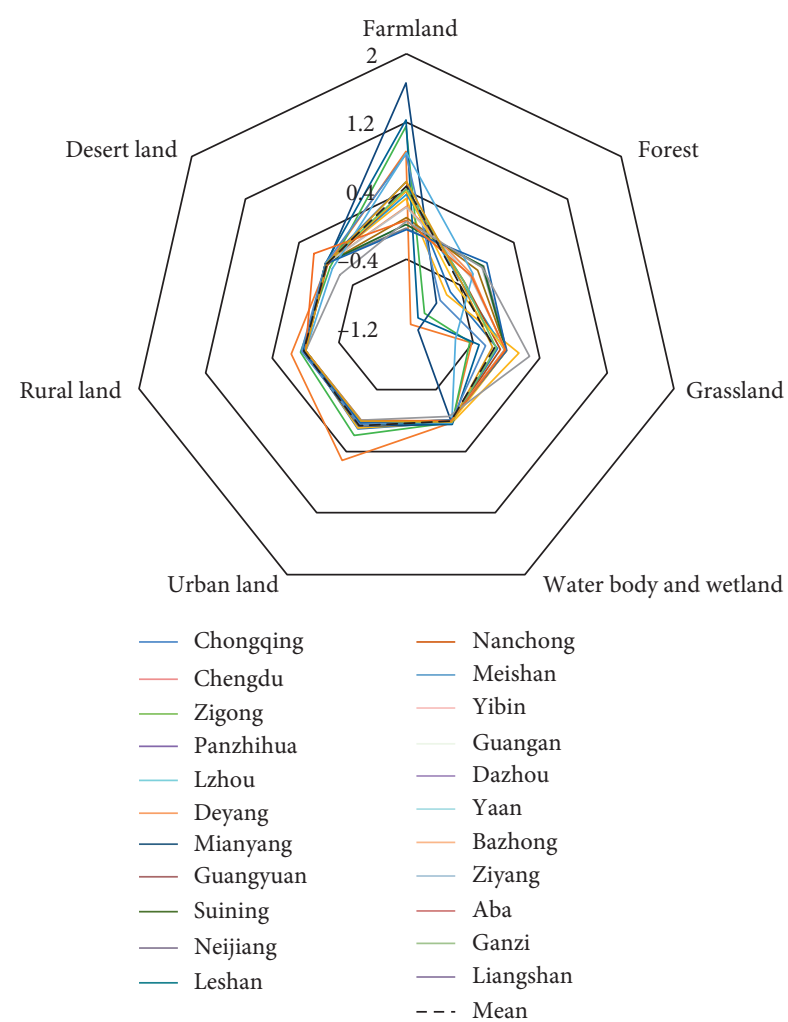

(b)
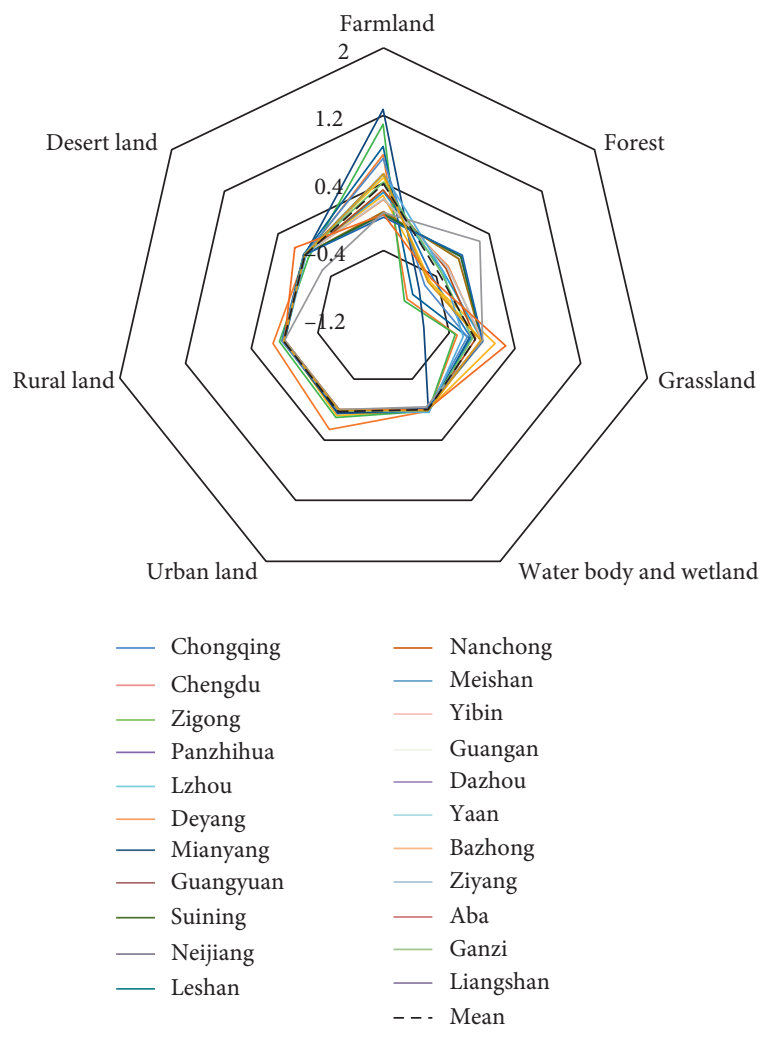

(d)

Figure 7: Continued. 

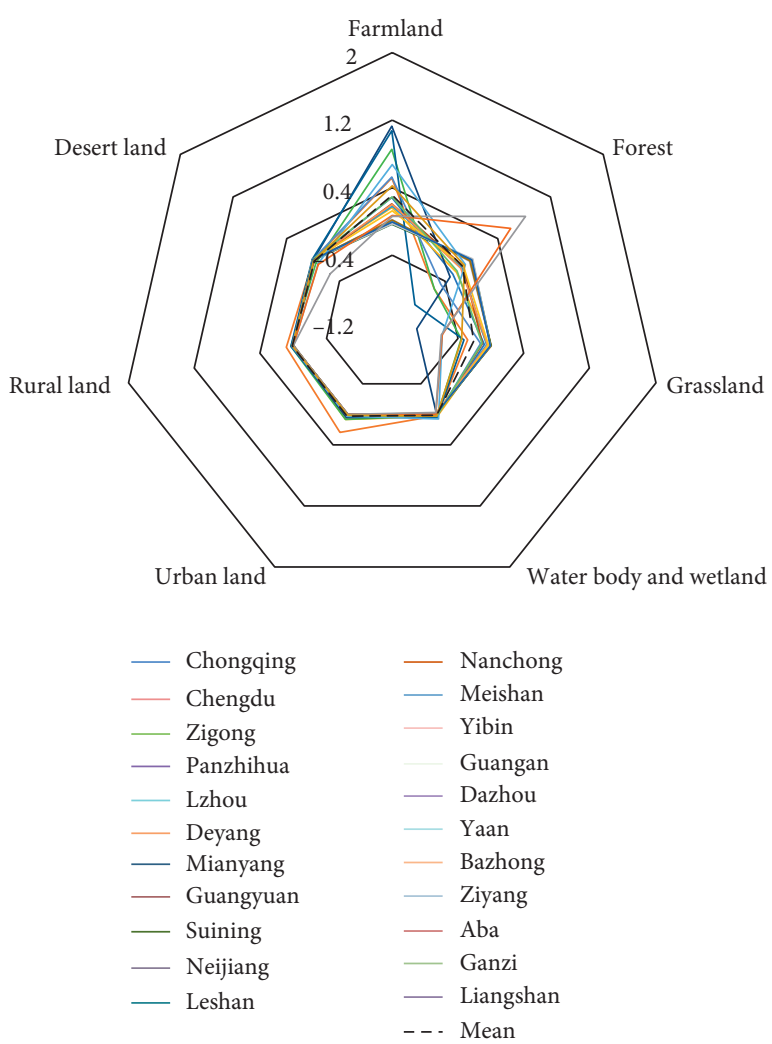

(e)
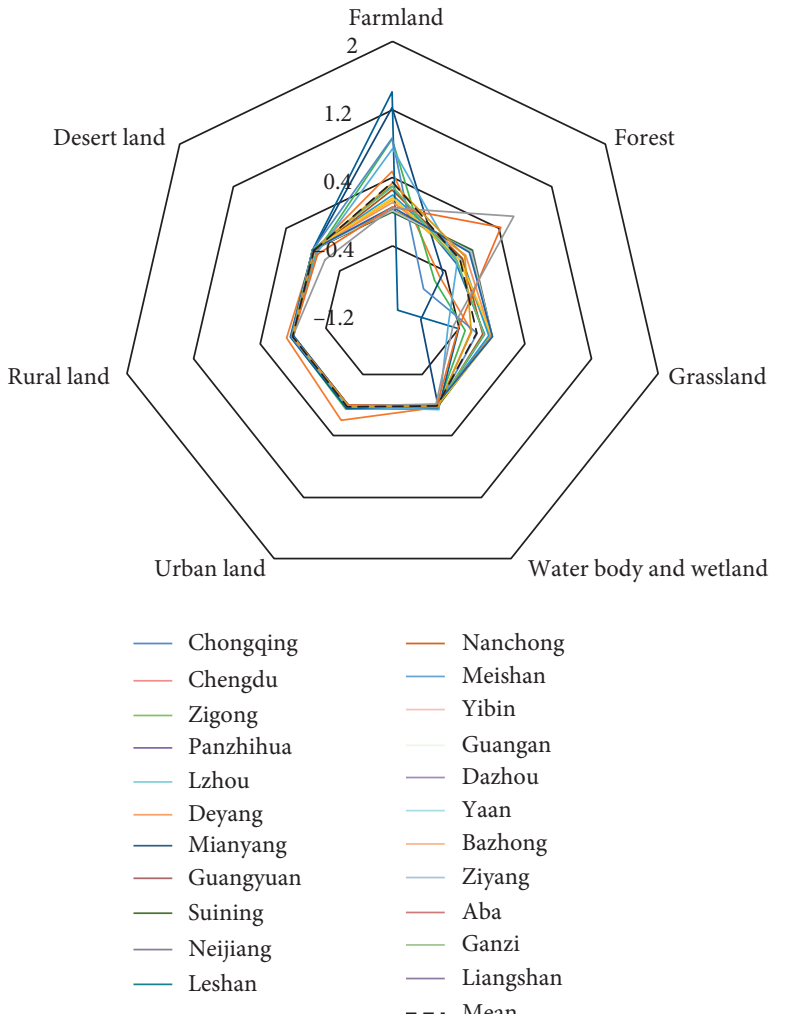

(g)
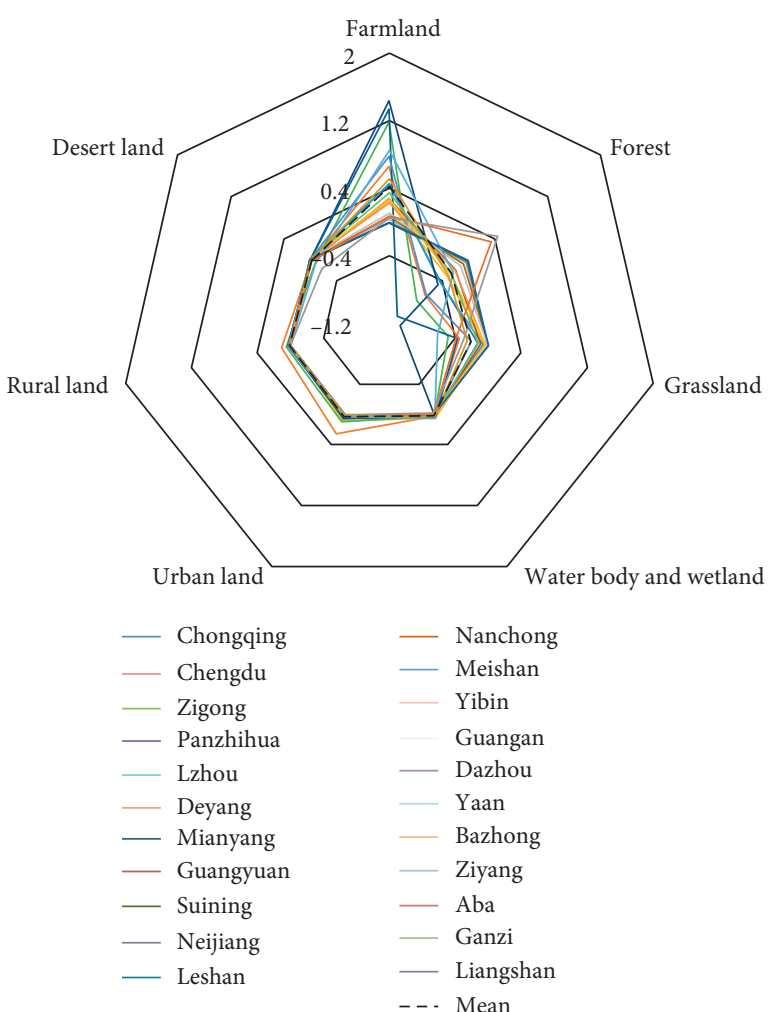

(f)
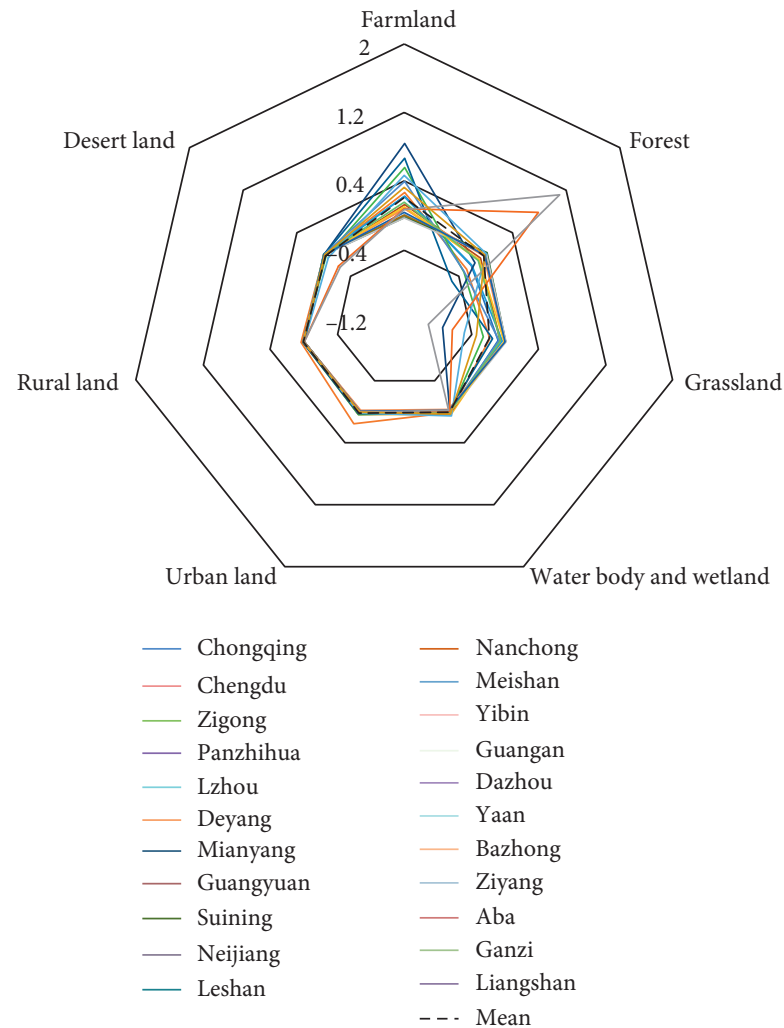

(h)

Figure 7: The CIs of ecosystem types for 22 cities in Sichuan-Chongqing region in 2015. (a) Spring daytime. (b) Summer daytime. (c) Autumn daytime. (d) Winter daytime. (e) Spring nighttime. (f) Summer nighttime. (g) Autumn nighttime. (h) Winter nighttime. 
the thermal environment increased significantly, reaching 1.11 and 0.78 , respectively. Comprehensive comparison of the contributions of ecosystems with urban thermal environment at the nighttime shows that there were obvious similarities between spring and autumn periods. Farmland and forest ecosystems were affected by seasons and phenology, exhibiting the different thermal environment source and sink characteristics, as well as intensity characteristics in different cities.

For the Sichuan-Chongqing region, the contributions of the farmland, forest, and grassland ecosystems to the thermal environment varied substantially, while the urban, farmland, and water and wetland ecosystems made relatively small contributions to the thermal environment. From the perspective of diurnal changes, the contributions of the same ecosystem type to the thermal environment of different cities varied more significantly during the daytime than at nighttime, and this variability was most obvious in the case of farmland ecosystems. Forest and grassland ecosystems experienced a role transition between heat source and heat sink of the thermal environment of cities. Urban and rural ecosystems always had a significant impact on the urban thermal environment as heat sources. In terms of seasonal changes, different ecosystem types were affected by solar radiation and phenological changes, and their contributions to the thermal environment demonstrated significant variability. Spring and autumn had similar thermal conditions, and the spatial and temporal characteristics of the ecosystem contribution indices to the thermal environment were similar. Summer and winter were affected by the thermal background field, and the contributions of different ecosystem types to the thermal environment were changing significantly. In addition, the differences in the area proportions and spatial pattern variability of ecosystems among different cities could also lead to significant differences in the contributions to their thermal environment.

\section{Discussion}

The Sichuan-Chongqing region is clearly affected by the topographic conditions, and the resulting coupling relationship between the ecosystem evolution and urban thermal environment is more unique than that of a plain area. With the acceleration of the urbanization process, farmland, forest, and grassland ecosystems were transformed into the urban ecosystems; however, the difference between the temperatures of the urban ecosystems and the average temperature decreased, indicating the decline of urban heat island intensity, and, consequently, certain contradictions exist. Considering the present relationship between the urban development and thermal environment development of the Sichuan-Chongqing region, it was observed that the intensity of the urban heat island of the new urban construction was less than that of the original urban construction. At the early stage of the new urban construction, it still acted as the heat sink of the thermal environment and alleviated the heat island effect of the original central area of cities. Obviously, the intensity of the new urban construction is far lower than that of the central area of cities, and there are many ecological lands in these areas that are not completely occupied by the buildings. On the other hand, due to the progress of planning concept and management measures, the greening measures and energy consumption technologies of the new urban construction would be significantly better than those of the original central area of cities. In summary, human activities in the SichuanChongqing region led to a convergence of the thermal environment, in which the original topographical elements and ecosystems worked together.

At present, researchers have conducted in-depth studies on the impact of land use types on the urban thermal environment and on urban heat island effect, specifically in terms of the influence mechanism corresponding to the urban construction land, blue-green space, and other spatial quantities and forms [26-28, 39-41]. However, existing research usually addressed the thermal environmental effects of a single type of land use, and research works focusing on the impact of multiple land use types on the spatial and temporal scales of the urban thermal environment were limited. In this paper, the thermal environment contribution indices were used to compare the interannual, seasonal, and diurnal effects of different ecosystem types on the thermal environment of the Sichuan-Chongqing region, so as to distinguish the heat source and sink ecosystems of the urban agglomeration and quantitatively calculate the degree of impact. The research results provide important practical value for tourism destinations to alleviate and regulate the urban thermal environment through spatial and functional design in the urban areas. The ecosystems can be managed to control the area of ecosystem types with heat source characteristics and development intensity from the perspective of regional thermal environment sources and sinks, seeking to avoid the deterioration of the thermal environment of cities caused by adverse conditions such as heat source agglomeration and sensible heat rise due to an increased area or utilization intensity. To prevent the deterioration of the climate environment of tourist destinations, it is necessary to consider the source and sink ecosystems of the thermal environment at the same time. In addition to preventing the disorderly expansion of the heat source ecosystem, especially in tourist destinations, it is of great significance to identify the type and contribution of heat sink ecosystems and give full play to their climate effects (including cooling in summer and keeping warm in winter) for attracting tourists.

The interesting discovery of the diurnal role transformation of urban heat source or sink has important application value for the choice of tourism destinations. These cities can be divided into the day-night heat source type, the day-sink and night-source type, and the day-night heat sink type according to the contributions of different cities to the regional thermal environment. Therefore, tourists can choose more suitable cities to carry out day travel or night activities according to their tourism preferences. We further use cluster analysis to cluster 22 cities in Sichuan-Chongqing region according to the contributions of various ecosystems to urban thermal environment (Figure 8). Although the altitude of Ganzi Yi Autonomous Prefecture and Aba Prefecture is significantly higher than that of other cities in 


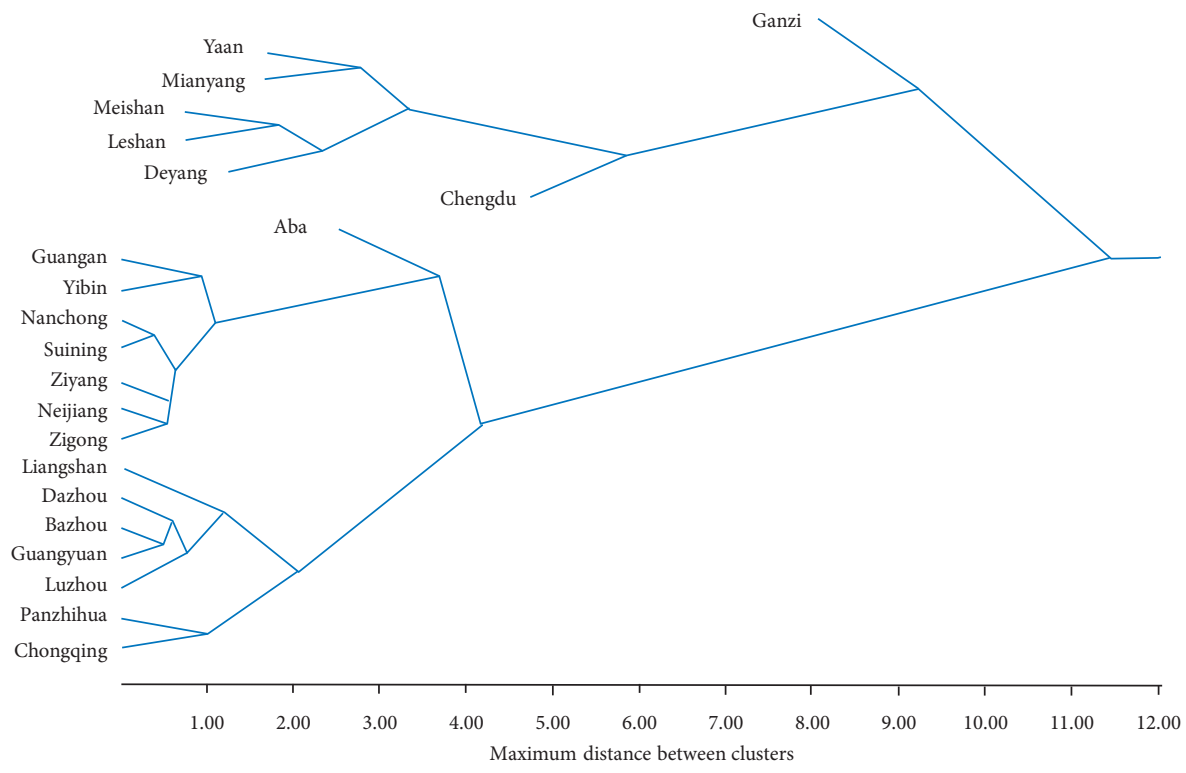

FIgURE 8: City clusters of urban thermal environment contributions of the ecosystems.

the region, Ganzi is totally different from other cities in that its negative contribution of desert ecosystem is far greater than that of other cities, and the positive contribution of grassland ecosystem is extremely significant, which is conducive to developing ice and snow tourism and grassland tourism. In Ya'an, Mianyang, Meishan, Leshan, Deyang, and Chengdu, of which Chengdu is the most obvious, the contributions of urban ecosystem to regional thermal environment are significantly higher than those in other cities. Meanwhile, forest ecosystem and grassland ecosystem also play obvious roles of heat sink. Therefore, the development of forest and grassland ecotourism may attract more tourists in these cities. However, it should be noted that the farmland ecosystem in these areas is the largest heat source. In other cities, the urban thermal environment contributions of various ecosystems are relatively insignificant. In these cities, only the forest ecosystem shows a certain cooling effect, but it is much weaker than the urban cluster represented by Chengdu City. Therefore, forest ecotourism can be carried out properly in these cities, but the quality of the forest ecosystem must be protected to maintain the urban comfortable climate.

However, there are many uncertainties in the study, which use contribution indices to investigate the impact of the source and sink ecosystems on the regional thermal environment. First, the thermal environment contribution index is characterized by the spatial variation in the ecosystem surface temperature with the area proportion of the ecosystem as the main common impact factor. However, there are practical requirements for scientific regulation of the regional thermal environment, which imply further separation of the individual effects of the ecosystem temperature and area on the regional thermal environment. Second, the thermal environment is affected not only by ecosystem types but also by topography, anthropogenic heat emissions, and atmospheric conditions. Further improvement of the thermal environment contribution index algorithm demands theoretical support on how to control the impact of these external factors on the research results to obtain more robust analysis outcome. Third, the spatial arrangement of ecosystem types was not considered in the application of the thermal environment contribution index. Various studies confirmed that ecosystems with different spatial arrangements produce different local climate effects. Therefore, the question of how to introduce the spatial form factor is the technical requirement for the further improvement of the future thermal environment contribution index algorithm. Fourth, regarding the research scale, the surface temperature data and ecosystem type data of $1 \mathrm{~km}$ spatial resolution can satisfy the research need for the Sichuan-Chongqing region. However, indepth study on the relationship between small-scale ecosystems and the thermal environment requires the improvement in both the spatial precision of the ecosystem and the high-resolution surface temperature data at the same time. This needs to be considered as a data requirement for further improvement of the thermal environment contribution accuracy in the future.

\section{Conclusions}

Considering the Sichuan-Chongqing region as the research object, according to the interannual, seasonal, and diurnal characteristics of the thermal environment coupled with three spatial scales at the levels of regions, cities, and ecosystems, this study summarized the source/sink role characteristics, differences in intensity, and variation trends of the contributions of different cities and ecosystems to the regional thermal environment using thermal environment contribution indices to provide theoretical and technical support for control and regulation of the thermal environment of the tourist destinations in the SichuanChongqing region. 
According to the contributions of different cities to the regional thermal environment, they can be divided into the day-night heat source type, the day-sink and night-source type, and the day-night heat sink type referring to Chongqing, Ganzi Yi Autonomous Prefecture, and Ya'an as typical representatives for each type, respectively. During the period of 2005-2015, the absolute values of the contribution indices of individual cities to the thermal environment of the Sichuan-Chongqing region increased, showing an increase in the intensity of heat sources and sinks of the thermal environment. Farmland, forest, and grassland ecosystems imposed significant impacts on the regional thermal environment, mainly in terms of impact area and impact intensity, and they were sensitive to seasonal changes. The contributions of urban and rural ecosystems to the thermal environment changed insignificantly in terms of seasonal changes. The contribution of ecosystem types to the regional thermal environment indicated seasonal and diurnal source/ sink changes, while their effects on the thermal environment of different cities exhibited more spatial heterogeneity. Considering tourism destinations in the rapid urbanization process, it is important to control the quantity and spatial arrangement of heat source ecosystems through the identification of the source and sink ecosystems in the thermal environment, fully utilize the cooling effect of the heat sink ecosystems so as to scientifically regulate the thermal environment effects of tourism destinations, and maintain the comfort level and sustainability of the destinations.

\section{Data Availability}

The surface temperature data used in this study are obtained from the moderate resolution imaging spectroradiometer (MODIS) 8-day synthetic surface temperature product (MYD11) provided by NASA. The ecosystem type data are obtained from the 1:100,000 China land use remote sensing monitoring dataset provided by the Resource and Environmental Science Data Cente of the Chinese Academy of Sciences. Requests for access to these data should be done through accessing https:/ladsweb.modaps.eosdis.nasa.gov/ and http://www.resdc.cn/Default.aspx, respectively.

\section{Conflicts of Interest}

The authors declare that they have no conflicts of interest.

\section{Acknowledgments}

This research was funded by National Natural Science Foundation of China (Grant nos. 41971389 and 41501472), Jiangsu Overseas Research and Training Program for University Prominent Young and Middle-Aged Teachers (2015), and the Strategic Priority Research Program of Chinese Academy of Sciences (Grant no. XDA20010302).

\section{References}

[1] J. Liu, H. Cheng, D. Jiang, and L. Huang, "Impact of climaterelated changes to the timing of autumn foliage colouration on tourism in Japan," Tourism Management, vol. 70, no. 7058, pp. 262-272, 2019.

[2] D. Scott, C. M. Hall, and S. Gössling, "A review of the IPCC Fifth assessment and implications for tourism sector climate resilience and decarbonization," Journal of Sustainable Tourism, vol. 24, no. 1, pp. 8-30, 2016.

[3] F. Yan, J. Yin, and B. Wu, "Climate change and tourism: a scientometric analysis using CiteSpace," Journal of Sustainable Tourism, vol. 26, no. 1, pp. 108-126, 2018.

[4] J. Zhang and L. Wu, "Modulation of the urban heat island by the tourism during the Chinese new year holiday: a case study in Sanya City, Hainan Province of China," Science Bulletin, vol. 60, no. 17, pp. 1543-1546, 2015.

[5] G. Hoogendoorn and J. M. Fitchett, "Tourism and climate change: a review of threats and adaptation strategies for Africa," Current Issues in Tourism, vol. 21, no. 7, pp. 742-759, 2016.

[6] S. Gössling, "Tourism, information technologies and sustainability: an exploratory review," Journal of Sustainable Tourism, vol. 25, no. 7, pp. 1024-1041, 2017.

[7] L. Chen and E. Ng, "Outdoor thermal comfort and outdoor activities: a review of research in the past decade," Cities, vol. 29, no. 2, pp. 118-125, 2012.

[8] D. Lai, W. Liu, T. Gan, K. Liu, and Q. Chen, "A review of mitigating strategies to improve the thermal environment and thermal comfort in urban outdoor spaces," Science of the Total Environment, vol. 661, pp. 337-353, 2019.

[9] D. Lai, D. Guo, Y. Hou, C. Lin, and Q. Chen, "Studies of outdoor thermal comfort in northern China," Building and Environment, vol. 77, pp. 110-118, 2014.

[10] F. R. A. Alfano, B. I. Palella, and G. Riccio, "Thermal environment assessment reliability using temperature-humidity indices," Industrial Health, vol. 49, no. 1, pp. 95-106, 2011.

[11] G. M. Budd, "Wet-bulb globe temperature (WBGT)-its history and its limitations," Journal of Science and Medicine in Sport, vol. 11, no. 1, pp. 20-32, 2008.

[12] P. Bröde, E. L. Krüger, F. A. Rossi, and D. Fiala, "Predicting urban outdoor thermal comfort by the universal thermal climate index UTCI-a case study in Southern Brazil," International Journal of Biometeorology, vol. 56, no. 3, pp. 471-480, 2012.

[13] J. Yang, Z. Zhang, X. Li, J. Xi, and Z. Feng, "Spatial differentiation of China's summer tourist destinations based on climatic suitability using the universal thermal climate index," Theoretical and Applied Climatology, vol. 134, no. 3-4, pp. 859-874, 2018.

[14] D. Chen, X. Xu, Z. Sun, L. Liu, Z. Qiao, and T. Huang, "Assessment of mountain urban heat environment risk: a case study in Chongqing metropolitan area, China," Sustainability, vol. 12, no. 1, p. 309, 2020.

[15] L. Feng, M. Zhao, Y. Zhou, L. Zhu, and H. Tian, "The seasonal and annual impacts of landscape patterns on the urban thermal comfort using landsat," Ecological Indicators, vol. 110, p. 105798, 2020.

[16] Q. Weng, "Thermal infrared remote sensing for urban climate and environmental studies: methods, applications, and trends," ISPRS Journal of Photogrammetry and Remote Sensing, vol. 64, no. 4, pp. 335-344, 2009.

[17] D. Zhou, J. Xiao, S. Bonafoni et al., "Satellite remote sensing of surface urban heat islands: progress, challenges, and perspectives," Remote Sensing, vol. 11, no. 1, p. 48, 2019.

[18] D. Li, W. Liao, A. J. Rigden et al., "Urban heat island: aerodynamics or imperviousness?" Science Advances, vol. 5, no. 4, Article ID eaau4299, 2019. 
[19] S. Peng, S. Piao, P. Ciais et al., "Surface urban heat island across 419 global big cities," Environmental Science \& Technology, vol. 46, no. 2, pp. 696-703, 2012.

[20] Z. Qiao, G. Tian, L. Zhang, and X. Xu, "“Influences of urban expansion on urban heat island in Beijing during 1989-2010," Advances in Meteorology, vol. 2014, Article ID 187169, 11 pages, 2014.

[21] A. Räsänen, K. Heikkinen, N. Piila, and S. Juhola, "Zoning and weighting in urban heat island vulnerability and risk mapping in Helsinki, Finland," Regional Environmental Change, vol. 19, no. 5, pp. 1481-1493, 2019.

[22] Z. Qiao, G. Tian, and L. Xiao, "Diurnal and seasonal impacts of urbanization on the urban thermal environment: a case study of Beijing using MODIS data," ISPRS Journal of Photogrammetry and Remote Sensing, vol. 85, pp. 93-101, 2013.

[23] M. Zhao, H. Cai, Z. Qiao, and X. Xu, "Influence of urban expansion on the urban heat island effect in Shanghai," International Journal of Geographical Information Science, vol. 30, no. 12, pp. 2421-2441, 2016.

[24] R. Yao, L. Wang, X. Huang, Y. Niu, Y. Chen, and Z. Niu, "The influence of different data and method on estimating the surface urban heat island intensity," Ecological Indicators, vol. 89 , pp. $45-55,2018$.

[25] T. Chakraborty and X. Lee, "A simplified urban-extent algorithm to characterize surface urban heat islands on a global scale and examine vegetation control on their spatiotemporal variability," International Journal of Applied Earth Observation and Geoinformation, vol. 74, pp. 269-280, 2019.

[26] W. Zhou, G. Huang, and M. L. Cadenasso, "Does spatial configuration matter? Understanding the effects of land cover pattern on land surface temperature in urban landscapes," Landscape and Urban Planning, vol. 102, no. 1, pp. 54-63, 2011.

[27] W. Zhou, Y. Qian, X. Li, W. Li, and L. Han, "Relationships between land cover and the surface urban heat island: seasonal variability and effects of spatial and thematic resolution of land cover data on predicting land surface temperatures," Landscape Ecology, vol. 29, no. 1, pp. 153-167, 2014.

[28] R. Sun and L. Chen, "How can urban water bodies be designed for climate adaptation?" Landscape and Urban Planning, vol. 105, no. 1-2, pp. 27-33, 2012.

[29] L. Feng, S. Guo, L. Zhu, Y. Zhou, and D. Lu, "Urban vegetation phenology analysis using high spatio-temporal NDVI time series," Urban Forestry \& Urban Greening, vol. 25, pp. 43-57, 2017.

[30] Z. Qiao, D. Zhang, X. Xu, and L. Liu, "Robustness of satellitederived land surface parameters to urban land surface temperature," International Journal of Remote Sensing, vol. 40, no. 5-6, pp. 1858-1874, 2019.

[31] J. Yang, J. Sun, Q. Ge, and X. Li, "Assessing the impacts of urbanization-associated green space on urban land surface temperature: a case study of Dalian, China," Urban Forestry \& Urban Greening, vol. 22, pp. 1-10, 2017.

[32] Y. Ma, X. Zeng, Y. Zhang et al., "Impact of the choice of land surface scheme on a simulated heatwave event: the case of Sichuan-Chongqing area, China," Advances in Meteorology, vol. 2017, Article ID 9545896, 17 pages, 2017.

[33] J. a. Shao, Y. Li, and J. Ni, "The characteristics of temperature variability with terrain, latitude and longitude in SichuanChongqing region," Journal of Geographical Sciences, vol. 22, no. 2, pp. 223-244, 2012.

[34] L. Gawuc and J. Struzewska, "Impact of MODIS quality control on temporally aggregated urban surface temperature and long-term surface urban heat island intensity," Remote Sensing, vol. 8, no. 5, p. 374, 2016.

[35] D. Zhou, S. Zhao, S. Liu, L. Zhang, and C. Zhu, "Surface urban heat island in China's 32 major cities: spatial patterns and drivers," Remote Sensing of Environment, vol. 152, pp. 51-61, 2014.

[36] J. Liu, M. Liu, H. Tian et al., "Spatial and temporal patterns of China's cropland during 1990-2000: an analysis based on Landsat TM data," Remote Sensing of Environment, vol. 98, no. 4, pp. 442-456, 2005.

[37] Z. Qiao and G. Tian, "Spatiotemporal diversity and regionalization of the urban thermal environment in Beijing," Journal of Remote Sensing, vol. 18, no. 3, pp. 715-734, 2014.

[38] X.-L. Chen, H.-M. Zhao, P.-X. Li, and Z.-Y. Yin, "Remote sensing image-based analysis of the relationship between urban heat island and land use/cover changes," Remote Sensing of Environment, vol. 104, no. 2, pp. 133-146, 2006.

[39] J. Peng, J. Jia, Y. Liu, H. Li, and J. Wu, "Seasonal contrast of the dominant factors for spatial distribution of land surface temperature in urban areas," Remote Sensing of Environment, vol. 215, pp. 255-267, 2018.

[40] Z. Qiao, C. Wu, D. Zhao et al., "Determining the boundary and probability of surface urban heat island footprint based on a logistic model," Remote Sensing, vol. 11, p. 1368, 2019.

[41] Z. Qiao, L. Liu, Y. Qin, X. Xu, B. Wang, and Z. Liu, "The impact of urban renewal on land surface temperature changes: a case study in the main city of Guangzhou, China," Remote Sensing, vol. 12, no. 5, p. 794, 2020. 